\title{
Patient and surgical factors affecting procedure duration and revision risk due to deep infection in primary total knee arthroplasty
}

Mona Badawy ${ }^{1,4^{*}}$, Birgitte Espehaug ${ }^{2}$, Anne Marie Fenstad ${ }^{3}$, Kari Indrekvam ${ }^{1,4}$, Håvard Dale ${ }^{4}$, Leif I. Havelin ${ }^{3,4}$ and Ove Furnes ${ }^{3,4}$

\begin{abstract}
Background: The aim of this study was to assess which patient and procedure factors affected both the risk of infection as well as procedure duration. Additionally, to assess if procedure duration affected the revision risk due to deep infection in total knee arthroplasty (TKA) patients and in a subgroup of low-risk patients.

Methods: 28,262 primary TKA with 311 revisions due to deep infection were included from the Norwegian Arthroplasty Register (NAR) and analysed from primary surgery from 2005 until 31st December 2015 with a 1 and 4 year follow up. The risk of revision due to deep infection was calculated in a multivariable Cox regression model including patient and procedure related risk factors, assessing Hazard Ratio (HR) with 95\% confidence interval (CI).

Results: Multivariate analysis showed statistically significant associations with revision due to deep infection and increased procedure duration for male patients, ASA3+ (American Society of Anesthesiologists) and perioperative complications. Procedure duration $\geq 110$ min (75 percentile) had a higher risk of deep infection compared to duration $<75$ min (25 percentile), in the unadjusted analysis ( $H R=1.8,95 \% \mathrm{Cl} 1.3-2.5, p=0.001$ ) and in the adjusted analysis ( $H R=1.5,95 \% \mathrm{Cl} 1.0-2.1, p=0.03$ ). For low-risk patients, procedure duration did not increase the risk of infection.

Conclusion: Male patients, ASA 3+ patients and perioperative complications were risk factors both for longer procedure duration and for deep infection revisions. Patients with a high degree of comorbidity, defined as ASA3+, are at risk of infection with longer procedure durations. The occurrence of perioperative complications potentially leading to a more complex and lengthy procedure was associated with a higher risk of infection. Long procedure duration in itself seems to have minor impact on infection since we found no association in the low-risk patient.
\end{abstract}

Keywords: Knee, Osteoarthritis, Arthroplasty, Procedure duration, Infection, Risk factors, Revision

\section{Background}

Numerous risk factors predispose patients to deep infection after total knee arthroplasty. It is critical to identify the correlation of risk factors that predispose TKA patients to deep infection, to reduce or even avoid this complication. Prolonged procedure duration has been

\footnotetext{
* Correspondence: mona.badawy@helse-bergen.no

${ }^{1}$ Coastal Hospital in Hagavik, 5217 Hagavik, Norway

${ }^{4}$ Department of Clinical Medicine, Institute of Medicine and Dentistry,

University of Bergen, 5021 Bergen, Norway

Full list of author information is available at the end of the article
}

demonstrated to increase the infection risk [1-5]. This is probably due to a combination of factors involving both the patient and the surgical environment, leading to bleeding and cautery, increased tissue damage and increased wound contamination.

Both surgeon and patient related factors can contribute to long procedure duration. Complexity of the surgery due to previous surgery to the knee or diagnoses other than primary osteoarthritis (OA) can increase procedure duration in addition to occurrence of perioperative complications. Inexperienced surgical team, low 
volume hospitals/surgeons could also contribute to longer procedure duration $[3,6]$. Patient related factors increasing procedure duration are male sex, comorbidities, obesity and previous fractures around the knee [7, 8]. These factors are also well known risk factors of infection $[1,9-15]$.

The 'Proceedings of the International Consensus Meeting on Periprosthetic Joint Infections' by Javad Parvizi and Thorsten Gehrke [16] agrees with 96\% delegate votes that surgical site infection rates increase directly with the duration of surgery. Their justification is numerous studies linking increased operative time to the risk of infection after total joint arthroplasty with statistical significance $[1-3,14,17]$. A study from Naranje et al. [12] demonstrated that operative time is only one of many factors that may increase infection risk and may be influenced by numerous confounders.

There are few reports on the relationship between long procedure duration and deep infection with revision as endpoint $[1,3,12]$, and few describe the factors leading to prolonged procedure duration $[8,18]$.

Large study populations are required to measure rare events like deep infection. We used registry data [19] to determine risk factors for both prolonged procedure duration and deep infection and if there was an association between longer procedure duration and revision risk resulting from deep infection after TKA.

\section{Methods}

TKA has been registered in the NAR since 1994. The completeness of reporting for primary procedures was $96 \%$ and $89 \%$ for revision surgery compared to data from the Norwegian Patient Registry [19]. In the present study, we included 28,262 primary TKA from 2005 to 2015. We selected the last 10 years of data to avoid outdated techniques and implants as well as less modern operating rooms. For homogeneity reasons, only cemented (with antibiotics) cruciate retaining (CR) implants (97\% in the NAR) without patellar components $(92 \%$ in the NAR) were included. Unicompartmental knee arthroplasty and more constrained implants were excluded (Fig. 1).

Revision was defined as complete or partial removal, exchange or addition of implant component(s). Patients with superficial wound infections treated with surgical site soft tissue debridement or with antibiotics only were

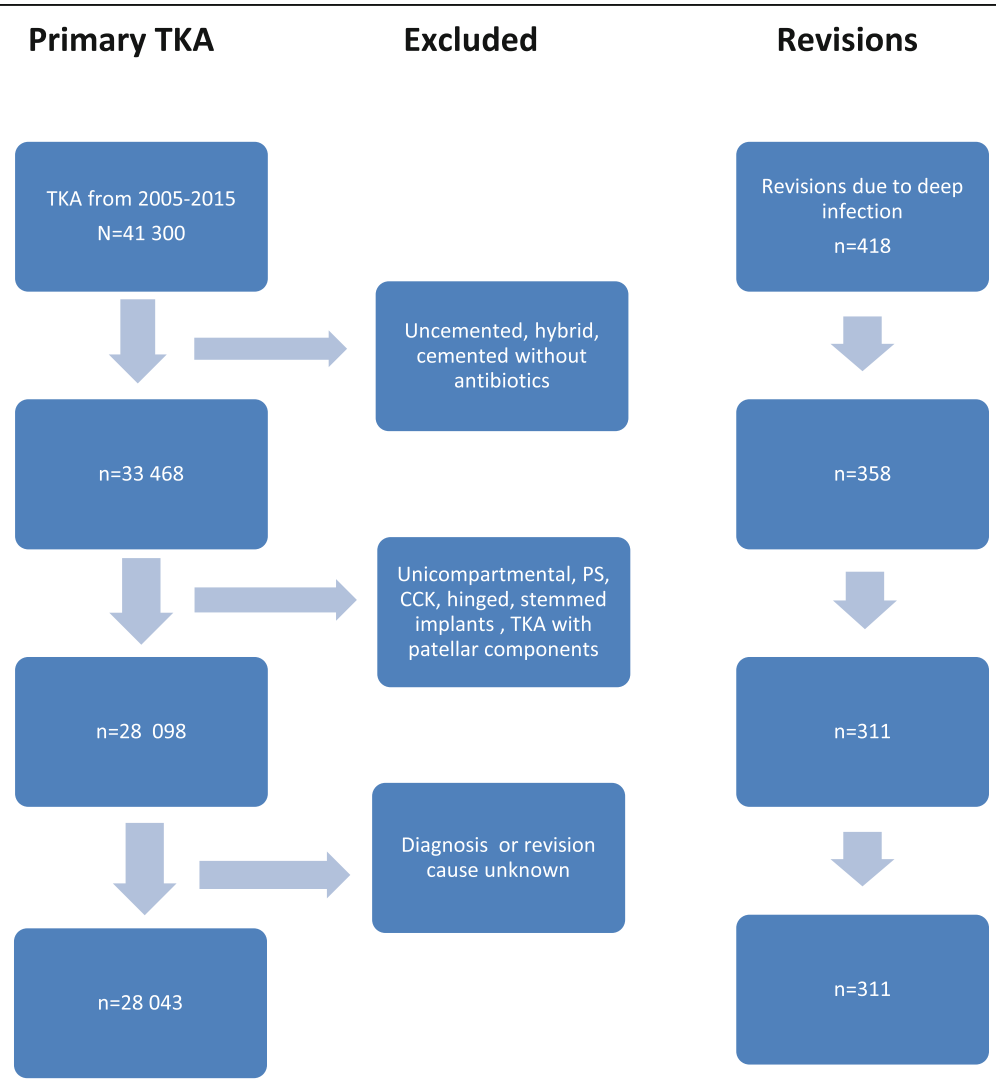

Fig. 1 Flow chart with inclusion and exclusion criteria for total knee arthroplasties (TKA) reported to the Norwegian Arthroplasty Register from 2005 to 2015. Knees treated with uncemented, hybrid, cemented without antibiotics, unicompartmental, PS (posterior stabilized), CCK (constrained condylar knee), hinged, stemmed implants and TKA with patellar component were excluded for homogeneity reasons. Only TKAs with known operation time were included 
not included in this study. A suggested follow-up time of 1 year would include all post-interventional infections thought to arise during implantation. Later there may be more haematogenous spread infections [20]. 1 and 4 years Kaplan Meier revision percentages are presented in Tables 3 and 4.

Procedure duration was recorded as the time from skin incision to complete wound closure in all cases. We used four different duration categories using quartiles (<75 min, 75-89 min, 90-109 $\mathrm{min}$ and $\geq 110$ ). Data on patient related risk factors were collected; age, sex, comorbidity score (ASA (American Society of Anesthesiologists) classification), diagnosis and previous fractures or osteotomy to the knee. Hospital and surgery related risk factors were also collected; annual hospital volume, the occurrence of perioperative complications, the use of computer navigation (CAOS), implant brand and time period (Table 1).

The majority of reported perioperative complications were different types of fractures, various tendon and ligament ruptures and technical issues regarding instruments or cementing, all increasing the probability of prolonged procedure duration.

Finally, a low-risk patient was defined based on the least probable risk of revision TKA from the analyses of all TKA presented in Tables 2 and 3; defined as a TKA patient with primary OA, classified as ASA 1 or 2, without any previous osteotomy or fracture to the knee and without any registered occurrence of perioperative complications.

\section{Statistics}

Survival analyses were performed with first revision due to deep infection as endpoint. All cases were censored at December 31st 2015 to achieve at least 1 year follow-up for all primary TKA. Information about deaths and emigrations were obtained from the National Population Register. 1- and 4-year revision probabilities (time to revision due to deep infection) for the four procedure duration categories were calculated using the Kaplan-Meier method.

A Cox regression model was used to calculate the possible association between procedure duration and implant survival. Hazard ratios (HR) were represented with $95 \%$ confidence intervals $(\mathrm{CI})$ and $p$-values relative to the shortest procedure duration as reference. All pvalues less than 0.05 were considered statistically significant.

Both unadjusted (crude) and adjusted multivariate Cox proportional hazard models were used. Adjustment for potential confounding was performed. The model included common patient-related variables such as age, sex, diagnosis and ASA classification. The occurrence of perioperative complications were strongly associated with prolonged procedure duration and were therefore added to the adjustment.

Similarly, unadjusted and adjusted Cox regression models were created for the low-risk patient previously described. Adjusted Cox regression curves were constructed for both models (Figs. 1 and 2).

The relative hazard assumption was tested by Schoenfeld residuals for chosen covariates and found to be valid. We found $13.3 \%$ bilateral procedures in our material and they were equally distributed in the infected and noninfected group. Death or emigration (lost to follow up) as a possible competing risk was investigated and there were no statistical significant differences in proportion of deaths within the groups, $p$-value equal to 0.15 .

SPSS version 22 and $R$ version 3.3.0 were used for the statistical analyses.

\section{Results}

28,262 primary TKA were included for analysis and 311 patients underwent revision surgery for deep infection after TKA (1.1\%) during the 11 year study period. Revisions due to infections accounted for $46 \%$ of all revisions within 1 year, and $27 \%$ within 4 years of follow up. Patient and surgery characteristics are presented in Table 1.

The mean and median procedure duration for noninfected cases was 94 and 90 min respectively, and for infected cases $100 \mathrm{~min}$ in both measures. The mean difference was statistically significant $(p<0.001)$.

Risk factors for prolonged procedure duration ( $\geq 110 \mathrm{~min}$ ) were male sex, young age, diagnosis other than OA (inflammatory arthritis, OA due to previous fracture, ligament injury or infection), ASA 3+ patients, previous surgery to the knee, low hospital volume, perioperative complications, the use of CAOS, time period from 2005 to 2009 and implant brand (Table 1).

Adjusting for the other variables, males had a two times increased risk of revision resulting from deep infection as compared to females $(\mathrm{p}<0.001)$. ASA $3+\mathrm{pa}-$ tients had a 1.8 times higher risk of revision due to deep infection compared to patients classified as ASA 1 and 2 $(p=0.003)$. The occurrence of perioperative complications resulted in a 2.1 times higher risk of revision due to deep infection $(p=0.004)$ (Table 2).

The unadjusted Cox regression analysis showed statistically significant increased risk of revision resulting from infection comparing the longest duration group $\geq 110 \mathrm{~min}$ to the shortest procedure duration of $<75 \mathrm{~min}$ by $\mathrm{HR}=1.8$ (95\% CI 1.3-2.5, $p=0.001$ ). (Table 3). After adjusting the Cox model for age, sex, diagnosis, ASA classification and the occurrence of perioperative complications, the effect of procedure duration was still statistically significant showing higher risk of revision due to deep infection in the longest duration group as 
Table 1 Patient and procedure characteristics at primary TKA relative to the four procedure duration groups

\begin{tabular}{|c|c|c|c|c|c|}
\hline & Procedure & Groups & & & \\
\hline & $<75 \min$ & $75-89$ & $90-109$ & $\geq 110$ & $p$-value \\
\hline Number of procedures & 5680 & 6238 & 8659 & 7685 & \\
\hline Year of operation 2010-2014 $(n=15,900) \%$ & 60 & 58 & 57 & 52 & $P<0.001$ \\
\hline Male sex $(n=10,186) \%$ & 28 & 31 & 37 & 44 & $P<0.001$ \\
\hline Age group \% & & & & & $P<0.001$ \\
\hline$<60(n=4989)$ & 15 & 17 & 17 & 21 & \\
\hline $60-69(n=9717)$ & 33 & 34 & 34 & 36 & \\
\hline 70-79 $(n=10,009)$ & 38 & 36 & 36 & 32 & \\
\hline$\geq 80(n=3547)$ & 14 & 13 & 13 & 11 & \\
\hline Median age (years) (range) & $71(31-96)$ & $70(25-94)$ & $70(23-101)$ & $68(22-93)$ & \\
\hline Median annual hospital volume & 118 & 113 & 95 & 86 & $P<0.001$ \\
\hline ASA \% & & & & & $P=0.001$ \\
\hline $1(n=4167)$ & 16 & 14 & 14 & 16 & \\
\hline $2(n=17,918)$ & 64 & 65 & 64 & 62 & \\
\hline $3+(n=5621)$ & 19 & 19 & 20 & 21 & \\
\hline Osteoarthritis $(n=25,152) \%$ & 92 & 90 & 88 & 87 & $P<0.001$ \\
\hline Perioperative complications ( $n=640$ ) \% & 0.7 & 1.1 & 1.8 & 4.9 & $P<0.001$ \\
\hline $\begin{array}{l}\text { Previous surgery for intraarticular fracture } \\
\text { or fracture near the joint }(n=551) \%\end{array}$ & 0.8 & 1.3 & 1.7 & 3.6 & $P<0.001$ \\
\hline Previous high tibial osteotomy $(n=885) \%$ & 1.9 & 2.5 & 2.8 & 4.9 & $P<0.001$ \\
\hline Computer navigated TKA $(n=2462) \%$ & 2.5 & 5.6 & 9.0 & 18 & $P<0.001$ \\
\hline Systemic antibiotics $(n=28,108) \%$ & 100 & 100 & 100 & 100 & $P=0.4$ \\
\hline Prosthesis brand \% & & & & & $P<0.01$ \\
\hline LCS Complete $(n=8752)$ & 26 & 31 & 31 & 34 & \\
\hline Profix $(n=6286)$ & 23 & 24 & 23 & 20 & \\
\hline NexGen $(n=4717)$ & 18 & 16 & 16 & 17 & \\
\hline AGC $(n=2233)$ & 15 & 7.3 & 6.1 & 5.1 & \\
\hline Duracon $(n=2043)$ & 5.7 & 6.8 & 6.8 & 9.2 & \\
\hline Triathlon $(n=1317)$ & 5.2 & 4.0 & 5.2 & 4.1 & \\
\hline Vanguard $(n=741)$ & 1.5 & 1.7 & 3.7 & 3.0 & \\
\hline PFC-Sigma $(n=697)$ & 1.3 & 2.6 & 3.0 & 2.7 & \\
\hline $\operatorname{LCS}(n=516)$ & 1.3 & 1.2 & 2.0 & 2.5 & \\
\hline Other $(n=955)$ & 3.3 & 5.0 & 2.9 & 2.7 & \\
\hline
\end{tabular}

compared to the shortest duration group; HR $=1.5$ (1.02.1, $p=0.03$ ) (Table 3, Fig. 2).

Procedure duration did not influence the risk of revision due to infection in the low-risk patient (described in the methods section) neither in the crude $(\mathrm{HR}=1.2,95 \%$ CI $0.8-1.9, p=0.3)$ or in the adjusted Cox regression analysis $\mathrm{HR}=1.1,95 \% \mathrm{CI} 0.7-1.7, p=$ 0.6) (Table 4, Fig. 3).

\section{Discussion}

Males, ASA 3+ patients, diagnosis other than OA and the occurrence of perioperative complications were factors associated with long procedure duration and increased risk of deep infection in this study (Table 2). In the low-risk patient we did not find evidence that increased procedure duration increased the risk of revision due to deep infection (Table 4). It could therefore be hypothesized that healthy patients that avoid perioperative complications tolerate longer procedure durations without getting infected.

Prolonged procedure duration may be caused by the complexity of the surgery and is thought to cause prolonged exposure time to microorganisms in the operating room and from the patient, possibly 
Table 2 Patient and procedure related risk factors for revision due to infection after primary TKA

\begin{tabular}{|c|c|c|c|c|c|}
\hline Variables & No & $\begin{array}{l}\text { RR }(95 \% \mathrm{Cl}) \\
\text { Unadjusted } \\
p \text {-value }\end{array}$ & & $\begin{array}{l}\text { RR (95\% Cl) } \\
\text { Adjusted }\end{array}$ & $p$-value \\
\hline \multicolumn{6}{|l|}{ Age } \\
\hline $60-69$ & 9717 & 1 & & 1 & \\
\hline$<60$ & 4989 & $0.9(0.7-1.3)$ & 0.7 & $0.9(0.7-1.3)$ & 0.6 \\
\hline $70-79$ & 10,009 & $0.8(0.6-1.0)$ & 0.1 & $0.8(0.6-1.1)$ & 0.1 \\
\hline$>80$ & 3547 & $0.7(0.5-1.1)$ & 0.1 & $0.7(0.5-1.1)$ & 0.1 \\
\hline \multicolumn{6}{|l|}{ Sex } \\
\hline men & 10,186 & 1 & & 1 & \\
\hline women & 18,076 & $0.5(0.4-0.6)$ & $<0.001$ & $0.5(0.4-0.6)$ & $<0.001$ \\
\hline \multicolumn{6}{|l|}{ Diagnosis } \\
\hline$O A^{a}$ & 25,152 & 1 & & 1 & \\
\hline Other $^{\mathrm{b}}$ & 3110 & $1.6(1.2-2.1)$ & 0.004 & $1.4(1.0-2.0)$ & 0.04 \\
\hline \multicolumn{6}{|l|}{ ASA } \\
\hline 1 & 4167 & 1 & & 1 & \\
\hline 2 & 17,918 & $1.1(0.8-1.5)$ & 0.7 & $1.2(0.8-1.7)$ & 0.4 \\
\hline $3+$ & 5621 & $1.7(1.2-2.5)$ & 0.005 & $1.8(1.2-2.7)$ & 0.003 \\
\hline \multicolumn{6}{|c|}{ Hospital volume } \\
\hline $1-49$ & 3953 & 1 & & 1 & \\
\hline $50-99$ & 10,615 & $1.1(0.8-1.6)$ & 0.5 & $1.1(0.8-1.6)$ & 0.5 \\
\hline $100-149$ & 6379 & $1.2(0.8-1.7)$ & 0.4 & $1.1(0.7-1.7)$ & 0.6 \\
\hline$\geq 150$ & 7315 & $1.2(0.8-1.7)$ & 0.4 & $1.1(0.7-1.7)$ & 0.6 \\
\hline \multicolumn{6}{|c|}{ Perioperative complications } \\
\hline no & 27,068 & 1 & & 1 & \\
\hline yes & 640 & $2.3(1.4-3.9)$ & 0.002 & $2.1(1.3-3.6)$ & 0.004 \\
\hline \multicolumn{6}{|c|}{ Computer navigation } \\
\hline no & 23,626 & 1 & & 1 & \\
\hline yes & 2462 & $1.0(0.7-1.5)$ & 1.0 & $1.0(0.7-1.5)$ & 1.0 \\
\hline \multicolumn{6}{|l|}{ Prior fracture ${ }^{c}$} \\
\hline no & 27,711 & 1 & & 1 & \\
\hline yes & 551 & $2.20(1.1-3.6)$ & 0.02 & $1.5(0.8-2.7)$ & 0.2 \\
\hline \multicolumn{6}{|c|}{ Prior osteotomy ${ }^{d}$} \\
\hline no & 27,377 & 1 & & 1 & \\
\hline yes & 885 & $0.9(0.5-1.8)$ & 0.8 & $0.8(0.4-1.5)$ & 0.5 \\
\hline \multicolumn{6}{|c|}{ TKA implant brands } \\
\hline LCS Complete & 8752 & 1 & & 1 & \\
\hline AGC & 2233 & $0.8(0.5-1.3)$ & 0.3 & $0.8(0.5-1.3)$ & 0.3 \\
\hline LCS & 516 & $1.1(0.5-2.3)$ & 0.9 & $1.3(0.6-2.9)$ & 0.5 \\
\hline Duracon & 2043 & $1.6(1.1-2.3)$ & 0.02 & $1.5(0.8-2.7)$ & 0.2 \\
\hline NexGen & 4717 & $1.2(0.8-1.6)$ & 0.4 & $1.0(0.7-1.4)$ & 1.0 \\
\hline Profix & 6286 & $0.9(0.6-1.2)$ & 0.4 & $0.9(0.6-1.2)$ & 0.4 \\
\hline PFC Sigma & 697 & $1.0(0.4-2.3)$ & 1.0 & $0.9(0.4-2.0)$ & 0.7 \\
\hline Triathlon & 1317 & $1.0(0.6-1.8)$ & 1.0 & $0.9(0.5-1.5)$ & 0.6 \\
\hline Vanguard TM & 741 & $0.3(0.1-1.0)$ & 0.06 & $0.2(0.1-0.8)$ & 0.03 \\
\hline Others $^{\mathrm{e}}$ & 955 & $0.4(0.1-1.0)$ & 0.05 & $0.4(0.1-1.0)$ & 0.06 \\
\hline
\end{tabular}


Table 2 Patient and procedure related risk factors for revision due to infection after primary TKA (Continued)

\begin{tabular}{|c|c|c|c|c|c|}
\hline Variables & No & $\begin{array}{l}\text { RR }(95 \% \mathrm{Cl}) \\
\text { Unadjusted } \\
p \text {-value }\end{array}$ & & $\begin{array}{l}\text { RR (95\% Cl) } \\
\text { Adjusted }\end{array}$ & $p$-value \\
\hline \multicolumn{6}{|l|}{ Time Period } \\
\hline $2005-2009$ & 12,362 & 1 & & 1 & \\
\hline 2010-2014 & 15,900 & $1.3(1.0-1.6)$ & 0.03 & $1.3(1.0-1.6)$ & 0.08 \\
\hline
\end{tabular}

contaminating the wound. We found that risk factors for prolonged procedure duration was male gender, probably due to more difficult exposure related to extensor muscle mass and more dense bone cuts [12]. Similarly, young age, ASA 3+, previous surgery to the knee, low hospital volume, diagnosis other than OA and the use of computer navigation increased the procedure duration (Table 1).

There are several other publications on the effect of duration of surgery on deep infection; Namba et al. [1] conducted a subanalysis regarding duration of surgery and found a 9\% increased risk per $15 \mathrm{~min}$ increment. Additionally, they found an increased risk of infection for male sex, ASA $3+$ and other diagnoses than OA comparable to our results. However, perioperative complications as a confounding factor were not included in that study. Willis-Owen et al. found that the mean duration of surgery in non-infected patients was 102 (60-315) minutes versus 125 (80-201) minutes in the infected group. They did not, however, include confounding factors of comorbidities in their analysis [21]. Perioperative complications were not included as a variable in that study. They found an increased risk of infection in the $>120$ min group [22]. Naranje et al. [12] concluded that there was an effect of duration of surgery, but as one of many factors.
Their conclusion was that after controlling for confounding variables, the effect of duration of surgery on risk of revision for infection was weak as an independent factor.

The strength of our study is the high number of primary TKA and the high completeness of registration in the NAR. Validation has found that $89 \%$ of all revisions after TKA were reported to the register from 2008 to 2012 [19]. However, there are some limitations to our study. The present study focuses solely on deep infection leading to revision of the knee arthroplasty either as debridement with exchange of the polyethylene bearing or as a complete 1 - or 2-staged procedure. Some registry studies have shown underestimation of the incidence of reoperations due to infection [23]. A previous study on total hip arthroplasty from the Danish Hip Arthroplasty register, using multiple data sources, found nearly $40 \%$ underreporting of prosthetic joint infections [24]. The total number of deep infections in the present study is therefore probably underestimated. However, it is unlikely that the underreporting of infection cases is unevenly distributed among the duration groups.

Why males are more prone to revision for infection is probably multifactorial, but the sex difference has

Table 3 Cox regression analysis. Risk of revision due to deep infection for all TKA patients in four different procedure duration groups

\begin{tabular}{|c|c|c|c|c|c|c|c|c|}
\hline \multirow[b]{3}{*}{ Procedure duration } & \multirow[b]{3}{*}{ No of TKA } & \multirow[b]{3}{*}{ No of revisions ${ }^{a}$} & \multirow[b]{3}{*}{ K-M 1y $\%^{b}$} & \multirow[b]{3}{*}{ K-M 4y $\%^{b}$} & \multicolumn{4}{|c|}{ Cox regression ${ }^{c}$} \\
\hline & & & & & \multicolumn{2}{|l|}{ Unadjusted } & \multicolumn{2}{|l|}{ Adjusted } \\
\hline & & & & & HR $(95 \% \mathrm{Cl})$ & $p$-value & HR (95\% Cl) & $p$-value \\
\hline & & & & & & $0.01^{d}$ & & $0.03^{d}$ \\
\hline$<75$ & 5680 & 48 & 0.60 & 0.89 & 1 & & 1 & \\
\hline $75-89$ & 6238 & 54 & 0.58 & 0.85 & $1.1(0.7-1.5)$ & 1.0 & $1.0(0.7-1.4)$ & 0.9 \\
\hline 90-109 & 8659 & 91 & 0.63 & 1.01 & $1.2(0.9-1.7)$ & 0.3 & $1.1(0.8-1.6)$ & 0.5 \\
\hline$\geq 110$ & 7685 & 118 & 0.91 & 1.38 & $1.8(1.3-2.5)$ & 0.001 & $1.5(1.0-2.1)$ & 0.03 \\
\hline
\end{tabular}

${ }^{a}$ Number of revisions due to deep infection $(n=311)$

${ }^{b}$ Kaplan-Meier estimated proportion of revisions due to deep infection at 1 and 4 years follow-up

'Unadjusted and adjusted Hazard ratios (HR) estimated with the Cox proportional hazards model (adjusted for sex, age, diagnosis, ASA classification and perioperative complications

dOverall test for group differences 


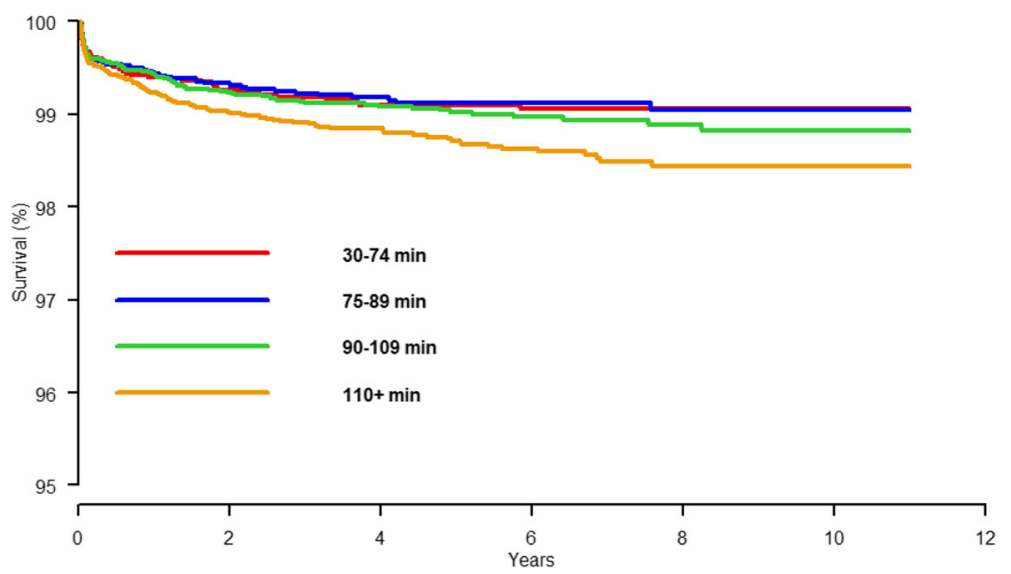

Fig. 2 Cox regression survival curve for all included primary TKA with revision due to deep infection as endpoint for four different procedure duration groups. Adjusted for sex, age, diagnosis, ASA classification and perioperative complications

been studied. Male's and female's skin differ in hormone metabolism, hair growth and sebum production [25]. There have been demonstrated sex differences in skin $\mathrm{pH}$ and skin thickness that are possible factors for the differences in skin colonisation [26, 27] and thereby the increased risk of infection discussed in several studies [1, 12]. Our study found evidence to support that males are at higher risk of revision due to infection after TKA.

Infection rates in orthopaedic surgery are low and therefore causal factors are difficult to determine. Endogenous transmission of for instance Staphylococci carriers has also been shown to be an important cause of surgical site infection [28, 29]. Males have a higher carrier frequency of staphylococci which may partly explain their twofold risk of revision due to infection compared to women found in several studies $[13,14]$.

Perioperative complications resulted in prolonged duration of surgery and also risk of revision due to deep infection after TKA in our study. The majority of perioperative complications were different types of fractures, various tendon and ligament ruptures and technical issues regarding instruments and cementing. This highlights the importance of avoiding complications through education of surgeons and theatre staff, preoperative planning, good theatre routines and increasing volume of surgery. Perioperative complications might necessitate extended surgical approaches and added implants and devices could potentially harm the soft tissues, increasing the risk of hematomas, potentially increasing the risk of infection.

BMI (Body mass index) and other risk factors such as smoking or diabetes are not registered individually in the NAR, and is a limitation to this study. However, it is captured in the ASA classification. ASA classification has been shown to be a strong predictor of wound infection [30]. Increasing BMI is also a contributing factor to increasing duration of surgery [7] and some studies has found a correlation between increased BMI and postoperative infection after TKA

Table 4 Cox regression analysis. Risk of revision due to deep infection for the low-risk patient ${ }^{\mathrm{a}}$ in four different procedure duration groups

\begin{tabular}{|c|c|c|c|c|c|c|c|c|}
\hline \multirow[b]{3}{*}{ Procedure duration } & \multirow[b]{3}{*}{ No of TKA } & \multirow[b]{3}{*}{ No of revisions ${ }^{\mathrm{b}}$} & \multirow[b]{3}{*}{ K-M 1y \% ${ }^{c}$} & \multirow[b]{3}{*}{ K-M $4 y \%^{c}$} & \multicolumn{4}{|c|}{ Cox regression $^{d}$} \\
\hline & & & & & \multicolumn{2}{|l|}{ Unadjusted } & \multicolumn{2}{|l|}{ Adjusted } \\
\hline & & & & & HR $(95 \% \mathrm{Cl})$ & $p$-value & HR $(95 \%$ Cl) & $p$-value \\
\hline$<75$ & 3232 & 31 & 0.68 & 1.00 & 1 & & 1 & \\
\hline 75-89 & 3718 & 30 & 0.57 & 0.84 & $0.8(0.5-1.4)$ & 0.5 & $0.8(0.5-1.3)$ & 0.4 \\
\hline 90-109 & 5130 & 44 & 0.49 & 0.78 & $0.9(0.6-1.4)$ & 0.6 & $0.8(0.5-1.3)$ & 0.4 \\
\hline$\geq 110$ & 4177 & 52 & 0.72 & 1.10 & $1.2(0.8-1.9)$ & 0.3 & $1.1(0.7-1.7)$ & 0.6 \\
\hline
\end{tabular}

${ }^{a}$ The low-risk TKA patient: TKA patient with primary osteoarthritis, ASA 1 or 2, without any previous surgery to the knee and no registered perioperative complications ( $n=16,257)$

${ }^{\mathrm{b}}$ Number of revisions due to deep infection $(n=157)$

'Kaplan-Meier estimated proportion of revisions due to deep infection at 1 and 4 years follow-up

'Unadjusted and adjusted Hazard ratios (HR) estimated with the Cox proportional hazards model, adjusted for sex and age 


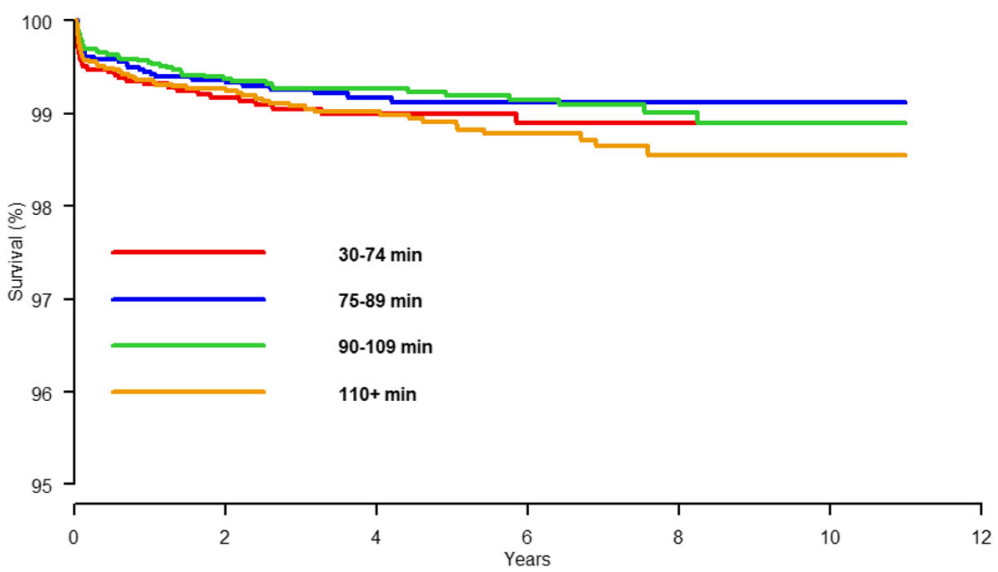

Fig. 3 Cox regression survival curve for "low-risk" primary TKA patients with revision due to deep infection as endpoint for four different procedure duration groups with adjustment for age and sex. "Low-risk" TKA patient: patient with primary osteoarthritis, with ASA 1 or 2, without any previous surgery to the knee and no registered perioperative complications

$[8,9]$. Others did not find similar relationship between obesity and infection [12]. Diabetes, irradiated skin, lymphedema, history of bleeding disorder could all lead to postoperative hematomas and woundrelated problems and be associated with persistent wound drainage and deep infection [31, 32]. Implant brand affected procedure duration for two different implants (Table 1). The reason for this variety could be hospital and surgeon dependent, or that some implants require more steps in the procedure itself. However, implant brand did not affect the risk of deep infection.

\section{Conclusion}

Male patients classified as ASA 3+, previous surgery to the knee and the occurrence of perioperative complications were factors requiring longer procedure duration and had a higher risk for infection after TKA in this study. Low-risk patients without perioperative complications did not have an increased risk of deep infection due to longer procedure durations. Long procedure duration in itself seems to have minor impact on infection since we found no association in the low-risk patient.

\section{Abbreviations}

ASA: American Society of Anesthesiologists; BMI: Body mass index; CAOS: Computer assisted orthopaedic surgery; Cl: Confidence interval; CR: Cruciate retaining; HR: Hazard ratio; K-M: Kaplan Meier; NAR: Norwegian Arthroplasty Røegister; OA: Osteoarthritis; TKA: Total knee arthroplasty

\section{Acknowledgements}

Not applicable.

\section{Funding}

This study had no funding. The Norwegian Arthroplasty Register is financed by the Western Norway Regional Health Authority (Helse-Vest).

\section{Availability of data and materials}

The datasets used/analysed during the current study are available from the corresponding author on reasonable request.

\section{Author's contributions}

$\mathrm{MB}, \mathrm{BE}, \mathrm{AMF}$ and $\mathrm{OF}$ designed the study. MB, BE, AMF, HD, KI, LIH and OF collected the data and edited the manuscript. MB wrote the manuscript and the analyses were done by AMF, BE, MB and OF. All authors have read and approved the final manuscript.

\section{Ethics approval and consent to participate}

The Norwegian Arthroplasty Register has concession from the Norwegian Data Protection Authority (last issued September 15 2014; reference number 03/00058-20/(GN) to collect and analyze patient data, based on a written consent from the patient The study has been performed in accordance with the ethical standards in the 1964 Declaration of Helsinki and the regulations of the US Health Insurance Portability and Accountability Act (HIPAA).

This study was approved through the ethical process of the national registry.

Patients in Norway give individual written concent to participate.

Consent for publication

Not applicable.

Competing interests

The authors declare that they have no competing interests.

\section{Publisher's Note}

Springer Nature remains neutral with regard to jurisdictional claims in published maps and institutional affiliations.

\section{Author details}

${ }^{1}$ Coastal Hospital in Hagavik, 5217 Hagavik, Norway. ${ }^{2}$ Center for Evidence-based Practice, Bergen University College, 5021 Bergen, Norway. ${ }^{3}$ The Norwegian Arthroplasty Register, Department of Orthopaedic Surgery, Haukeland University Hospital, 5021 Bergen, Norway. ${ }^{4}$ Department of Clinical Medicine, Institute of Medicine and Dentistry, University of Bergen, 5021 Bergen, Norway.

Received: 18 October 2017 Accepted: 14 December 2017 Published online: 21 December 2017

\section{References}

1. Namba RS, Inacio MC, Paxton EW. Risk factors associated with deep surgical site infections after primary total knee arthroplasty: an analysis of 56,216 knees. J Bone Joint Surg Am. 2013:95:775-82.

2. Carroll K, Dowsey M, Choong P, Peel T. Risk factors for superficial wound complications in hip and knee arthroplasty. Clin Microbiol Infect. 2014;20:130-5.

3. Peersman G, Laskin $R$, Davis J, Peterson MG, Richart T. Prolonged operative time correlates with increased infection rate after total knee arthroplasty. 
HSS journal: the musculoskeletal journal of Hospital for Special Surgery. 2006;2:70-2.

4. Smabrekke A, Espehaug B, Havelin LI, Furnes O. Operating time and survival of primary total hip replacements: an analysis of 31,745 primary cemented and uncemented total hip replacements from local hospitals reported to the Norwegian Arthroplasty register 1987-2001. Acta Orthop Scand. 2004;75:524-32.

5. Campbell DA, Jr., Henderson WG, Englesbe MJ, Hall BL, O'Reilly M, Bratzler $D$, et al. Surgical site infection prevention: the importance of operative duration and blood transfusion-results of the first American College of Surgeons-National Surgical Quality Improvement Program Best Practices Initiative. J Am Coll Surg 2008;207: 810-820.

6. Strum DP, Sampson AR, May JH, Vargas LG. Surgeon and type of anesthesia predict variability in surgical procedure times. Anesthesiology. 2000;92:1454-66.

7. Raphael IJ, Parmar M, Mehrganpour N, Sharkey PF, Parvizi J. Obesity and operative time in primary total joint arthroplasty. The journal of knee surgery. 2013;26:95-9.

8. Liabaud B, Patrick DA, Jr., Geller JA. Higher body mass index leads to longer operative time in total knee arthroplasty. J Arthroplast 2013;28: 563-565.

9. Maoz G, Phillips M, Bosco J, Slover J, Stachel A, Inneh I, et al. The Otto Aufranc award: modifiable versus nonmodifiable risk factors for infection after hip arthroplasty. Clin Orthop Relat Res. 2015;473:453-9.

10. Baker P, Petheram T, Jameson S, Reed M, Gregg P, Deehan D. The association between body mass index and the outcomes of total knee arthroplasty. The Journal of bone and joint surgery American. 2012;94:1501-8.

11. Dale H, Skramm I, Lower HL, Eriksen HM, Espehaug B, Furnes O, et al. Infection after primary hip arthroplasty: a comparison of 3 Norwegian health registers. Acta Orthop. 2011;82:646-54.

12. Naranje S, Lendway L, Mehle S, Gioe TJ. Does operative time affect infection rate in primary total knee arthroplasty? Clin Orthop Relat Res. 2015;473:64-9.

13. Kurtz SM, Ong KL, Lau E, Bozic K, Berry D, Parvizi J. Prosthetic joint infection risk after TKA in the Medicare population. Clin Orthop Relat Res. 2010;468:52-6.

14. Pedersen AB, Svendsson JE, Johnsen SP, Riis A, Overgaard S. Risk factors for revision due to infection after primary total hip arthroplasty. A populationbased study of 80,756 primary procedures in the Danish hip Arthroplasty registry. Acta Orthop. 2010;81:542-7.

15. Dale H, Fenstad AM, Hallan G, Havelin LI, Furnes O, Overgaard S, et al. Increasing risk of prosthetic joint infection after total hip arthroplasty. Acta Orthop. 2012;83:449-58.

16. Parvizi J, Gehrke T, Chen AF. Proceedings of the international consensus on Periprosthetic joint infection. The bone \& joint journal. 2013:95-b:1450-2.

17. Skramm I, Saltyte Benth J, Bukholm G. Decreasing time trend in SSI incidence for orthopaedic procedures: surveillance matters. The Journal of hospital infection. 2012;82:243-7.

18. Lozano LM, Nunez M, Segur JM, Macule F, Sastre S, Nunez E, et al. Relationship between knee anthropometry and surgical time in total knee arthroplasty in severely and morbidly obese patients: a new prognostic index of surgical difficulty. Obes Surg. 2008;18:1149-53.

19. NorwegianArthroplastyRegister. Norwegian Arthroplasty register annual report 2015. Rapport2015.pdf.

20. Kapadia BH, Berg RA, Daley JA, Fritz J, Bhave A, Mont MA. Periprosthetic joint infection. Lancet. 387:386-94.

21. Willis-Owen CA, Konyves A, Martin DK. Factors affecting the incidence of infection in hip and knee replacement: an analysis of 5277 cases. The Journal of bone and joint surgery British volume. 2010;92:1128-33.

22. Ridgeway S, Wilson J, Charlet A, Kafatos G, Pearson A, Coello R. Infection of the surgical site after arthroplasty of the hip. The Journal of bone and joint surgery British volume. 2005;87:844-50.

23. Jamsen E, Huotari K, Huhtala H, Nevalainen J, Konttinen YT. Low rate of infected knee replacements in a nationwide series-is it an underestimate? Acta Orthop. 2009:80:205-12.

24. Gundtoft PH, Overgaard S, Schonheyder HC, Moller JK, KjaersgaardAndersen P, Pedersen AB. The "true" incidence of surgically treated deep prosthetic joint infection after 32,896 primary total hip arthroplasties. Acta Orthop. 2015:1-9.

25. Giacomoni PU, Mammone T, Teri M. Gender-linked differences in human skin. J Dermatol Sci. 2009;55:144-9.

26. Fierer N, Hamady M, Lauber CL, Knight R. The influence of sex, handedness, and washing on the diversity of hand surface bacteria. Proc Natl Acad Sci U S A. 2008:105:17994-9.
27. Dao H Jr, Kazin RA. Gender differences in skin: a review of the literature. Gender medicine. 2007:4:308-28.

28. Mansson E, Hellmark B, Sundqvist M, Soderquist B. Sequence types of Staphylococcus Epidermidis associated with prosthetic joint infections are not present in the laminar airflow during prosthetic joint surgery. APMIS. 2015;123:589-95.

29. Skramm I, Fossum Moen AE, Aroen A, Bukholm G. Surgical site infections in Orthopaedic surgery demonstrate clones similar to those in Orthopaedic Staphylococcus Aureus nasal carriers. J Bone Joint Surg Am. 2014;96:882-8.

30. Woodfield JC, Beshay NM, Pettigrew RA, Plank LD, van Rij AM. American Society of Anesthesiologists classification of physical status as a predictor of wound infection. ANZ J Surg. 2007;77:738-41.

31. Simons MJ, Amin NH, Scuderi GR. Acute wound complications after Total knee Arthroplasty: prevention and management. The Journal of the American Academy of Orthopaedic Surgeons. 2017;25:547-55.

32. Galat DD, McGovern SC, Larson DR, Harrington JR, Hanssen AD, Clarke HD. Surgical treatment of early wound complications following primary total knee arthroplasty. J Bone Joint Surg Am. 2009;91:48-54.

\section{Submit your next manuscript to BioMed Central and we will help you at every step:}

- We accept pre-submission inquiries

- Our selector tool helps you to find the most relevant journal

- We provide round the clock customer support

- Convenient online submission

- Thorough peer review

- Inclusion in PubMed and all major indexing services

- Maximum visibility for your research

Submit your manuscript at www.biomedcentral.com/submit
Biomed Central 